\title{
The Effect of Professional Sports on the Earnings of Individuals: Evidence from Microeconomic Data
}

\author{
Dennis Coates ${ }^{\dagger}$ and Brad R. Humphreys ${ }^{\dagger \dagger}$
}

July 2006

\begin{abstract}
This paper explores the impact of professional sports teams and stadiums on the wages of individuals employed in several narrowly defined occupational groups in cities in the United States. The occupational groups examined are among those that proponents of public funding of professional sports claim will benefit economically from these stadiums. Our analysis uses data from the March Supplement to the Current Population Survey (CPS) for the period 1983 to 1998. Previous research focused on aggregate measures of income whereas here the focus is on the wages of individual workers. The results of the study conform conclusions of earlier research that the overall sports environment is frequently statistically significant as a determinant of earnings.
\end{abstract}

JEL Classification Codes: L83, R58, J30, H71

Keywords: sports economics, wages

${ }^{\dagger}$ Department of Economics, University of Maryland, Baltimore County, (410) 455-3243 (office), coates@umbc.edu

${ }^{\dagger \dagger}$ Department of Recreation, Sport and Tourism, 104 Huff Hall, 1206 South Fourth Street, Champaign, IL 61820, (217) 333-4410 (phone), (217) 244-1935 (fax), brh@uiuc.edu 


\section{Introduction and Motivation}

The economic impact of professional sports on local economies has emerged as an important economic policy issue in recent years. One reason for this is the increase in the construction of publicly funded professional sports stadiums and arenas. Over forty five new stadiums and arenas have been built for professional football, basketball and baseball teams since the mid 1980s and many more are currently under construction, in the planning phase, or have been proposed. Most of these construction projects receive substantial government subsidies, and proponents of this subsidization claim increases in employment, income and other economic benefits justify these subsidies. Prospective "economic impact" studies, commissioned and paid for by proponents of public subsidization of sports construction projects, claim to quantify these economic benefits. Siegfried and Zimbalist (2000) recently surveyed this issue.

Opponents of stadium and arena construction counter that the spending and income generation effects of sports are quite limited. Spending on sports substitutes for spending on other types of entertainment, and on other goods and services more generally, so there is very little new income (or employment) generated. ${ }^{1}$ Indeed, Coates and Humphreys (1999), (2001) provide evidence that professional sports reduce local incomes. Coates and Humphreys (2003) examine the impact of professional sports on earnings and employment in the retail and services sectors of local economies, including the eating and drinking establishments, hotels and other lodgings, and amusements and recreation sectors. This research uses relatively aggregated data from a single source, the Regional Economic Information System (REIS) collected and distributed by the Bureau of Economic Analysis.

This paper extends recent research by Carlino and Coulson (2004), who estimate both hedonic rent and wage equations including a dummy variable indicating the presence of an NFL franchise in a MSA. While they find a positive and significant effect of the NFL on rents, their estimates of an NFL effect on wages are not significant and frequently negative. Carlino and Coulson (2004) use data on individuals from the March Supplements to the

\footnotetext{
${ }^{1}$ See Baade and Dye (1988), (1990); Baade (1996); Baade and Sanderson (1997); Rosentraub, Swindell, Przybylski and Mullins (1994); Rosentraub (1997)
} 
Current Population Survey, but they include only observations from 1993 and 1999 in cities that lost or gained NFL franchises over this period, and do not identify sectors as more or less related to professional sports. One explanation for their finding that the presence of an NFL franchise does not have a statistically significant impact on the ratio of annual earnings to hours worked (average hourly wages) is that they are asking too much of the NFL variable. Boosters of professional sports typically argue that sports have a large impact on wages and employment in specific industries, lodging, bars, and restaurants, for example, not that sports raises wages equally in all sectors.

We narrow the focus of our estimation relative to Carlino and Coulson (2004) to examine the effects of the professional sports environment in cities on the earnings of men employed in a number of specific occupational groups in the service and retail sectors: food service, hotel services, retail sales, and sports and recreation. Like typical human capital wage equations, our models include controls for individual characteristics and local labor market conditions. We augment a typical human capital wage equation with variable which identify the presence of a team or teams from the NFL, NBA, or MLB in each city in order to assess the effect of professional sports on the weekly earnings of individuals. We focus on the ability of these franchise variables to explain wages of individual workers in those sectors of the economy most closely linked to the sports environment - eating and drinking establishments, hotels and other lodging, and retail sales and sports and recreation - in order to assess the economic impact of sports. If the pro-stadium/pro-sports-led-development argument is correct, then one should find higher wages in each of these occupations associated with a richer sports environment in a city. If the anti stadium led development argument is correct then one might find decreases in, or no effect on, wages of these workers.

The empirical evidence presented here suggests that the presence of professional sports franchises affects the wages of individuals working in some of these sectors. However, the sports environment variables may reduce wages rather than increasing them, at least in in some activities, suggesting that sports may be an unproductive amenity in these industries. Thus, the results of this individual level analysis confirms the findings of Coates and Humphreys (2003) on the data aggregated by sector and is consistent with the overall negative impact reported by Coates and Humphreys (2001), (1999) using similar data. On the 
other hand, we find positive and statistically significant effects on weekly wages of the presence of an NFL franchise. The size of these effects differs across industries, but is positive and significant in every specification.

\section{Empirical Models of Wage Determination}

A large body of literature exists on the determinants of the wages of individual workers. ${ }^{2}$ This literature uses human capital, proxied by experience and education, indicators for riskier activities, union membership and other variables to explain variation in the wages of individuals. Here, we posit a wage equation that depends upon the characteristics of the individual worker, local labor market conditions captured in city and year specific effects, and the professional sports environment in the city. In other words, our approach controls for the characteristics of individual workers and other factors and determines whether or not the professional sports environment has any ability to explain variation in wages not already explained by the other variables. This approach also allows us to compute the contribution of the sports environment to wages earned by workers whose livelihood is, according to stadiumled growth advocates, most likely to benefit from improvements to the sports environment.

This research is related to a large literature examining the effect of amenities on wages. ${ }^{3}$ Following the research by Roback (1982), the common approach in this literature has been to estimate wage equations, controlling for observable factors like race, gender, age, experience and education, for separate occupational groups and also including proxy variables for various amenities like good weather or access to the ocean. Here, we look for evidence that professional sports explains variation in wages of individuals, but the underlying causal relationship is direct - professional sports may alter the pattern of entertainment spending in a city and thus the earnings of workers in occupations related to entertainment spending - rather than an indirect effect due to a compensating wage differential.

\footnotetext{
${ }^{2}$ See Topel (1986) and Murphy and Welch (1992) for examples of studies of the determinants of wages based on times series of cross-sections drawn from the Current Population Survey (CPS) March Supplements.

${ }^{3}$ Rent gradients for amenities have also been estimated. See, for example Ridker and Henning (1967) and Diamond and Gerety (1995). Here we focus on estimating wage gradients for sports due to limited data on property values and rents.
} 
Examining the wages of workers in different occupational groups allows us to address an important area of debate in the literature on the public subsidization of professional sports. Advocates of sports led economic growth frequently claim that the beneficial economic impact of sports will be concentrated in specific sectors of the economy. New teams and stadiums will attract people to the area around the stadium where they will spend money on food and beverages, hotels, and consumer items such as souvenirs and team paraphernalia. This new consumer spending will drive up demand for waitresses and waiters, hotel staff, and sales clerks, resulting in higher wages by people employed in these jobs.

Opponents of using subsidies to professional sports as a tool of economic development suggest that the job and income creation effects of franchises and stadiums will be minimal. ${ }^{4}$ Opponents argue that much of the sales of food and drink and retail merchandize that arises around the stadium will simply substitute for similar sales at establishments in the city that are relatively distant from the stadium. Moreover, consumers may substitute attendance at sporting events for other types of recreational activities, such as attending movies or the theater or going bowling. If this argument is correct then one would expect to find no effect of the sports environment on the wages of workers in the Eating and Drinking, Hotels, and Amusements sectors of the economy.

The dependent variable in the wage equation, $w_{i j c t}$, is the log of real average weekly earnings of individual $i$ employed in occupation $j$ living in city $c$ in year $t$. Following the general practice in the literature on the determination of wages, the determinants of $\log$ wages are a vector of variables describing the economic and business climate in city $c$ during year $t$, as well as factors specific to individual $i$ working in occupation $j$ living in city $c$ in year $t, x_{i j c t}$, and a vector of variables which capture the presence of professional sports franchises in city $c$ in year $t, z_{c t}$. The empirical wage equation is

$$
w_{i j c t}=\beta x_{i j c t}+\gamma z_{c t}+\mu_{i j c t}
$$

where $\beta$ and $\gamma$ are vectors of parameters to be estimated and $\mu_{i t}$ is a disturbance term. By assumption, the disturbance term takes the form

\footnotetext{
${ }^{4}$ See, for example, the volume edited by Noll and Zimbalist (1997b).
} 


$$
\mu_{i j c t}=e_{i t}+v_{c}+w_{j}+u_{t}
$$

where $v_{c}$ is a disturbance specific to MSA $c$ which persists throughout the sample period, $u_{t}$ is a time $t$ specific disturbance which affects all cities, $w_{j}$ is an occupation specific effect which affects all individuals employed in a given occupation, and $e_{i c t}$ is a random shock to the wages of individual $i$ employed in occupation $j$ in MSA $c$ at time $t$ which is uncorrelated across individuals within and between MSAs and occupations and over time. Estimated this way, the regression purges the wage of the effect of national events on each jurisdiction in a given year and generates an MSA specific effect and an occupation specific effect. In other words, the level of wages in the market for hotel workers, say, in an MSA at any point in time is determined by time- and location-specific events, the characteristics of individual hotel workers, unobservable factors that affect all hotel workers in all cities, and the presence of professional sports franchises.

In equation (1), $x_{i j c t}$ is a vector of variables that control for factors other than the professional sports environment that affect wages of individual workers. These variables are described in more detail below, but they include race, age, and educational descriptors. We estimate the model pooling all the individuals, including occupation-specific dummy variables as regressors, and separately for two subgroupings of occupations based on whether they are directly or indirectly connected to the sports environment. By including the occupation variables in the pooled regression we can control for various unmeasured characteristics, including different levels of risk, associated with the various jobs.

The vector of sports environment variables, $z_{c t}$, contains an indicator variable for the presence of a professional football, basketball or baseball franchise in each of the 37 cities that currently have or had a franchise at some time in the period from 1983 through 1999.

All of the variables in equation (1) with an $i$ subscript vary by individuals, but the vector of sports environment variables only vary across cities, not across individuals. Moulton (1990) pointed out that this clustering of observations can lead to downward bias in the usual OLS standard errors. We correct the standard errors for clustering of the observations using the two-step correction suggested by Wooldridge (2003). 


\section{Data}

Our analysis focuses on the effect of professional sports franchises on the wages of individuals while controlling for demographic characteristics and the specific occupation of the workers. The list of occupational groups was developed based on our judgement and the typical argument that some sectors of the economy are more closely influenced by the sports environment than others. We examined the list of occupational groups and selected those that appear to be directly or indirectly related to professional sports. These occupations include food service workers, such as waiters and waitresses, cooks, busboys, and restaurant managers, lodging workers, such as hotel clerks, maids, and bellhops, retail sales workers, including cashiers and sales personnel and sales managers, and workers in the amusements and recreation industry, including athletes, ushers, and radio and television announcers. Data on individuals reporting one of these occupations was extracted from the Current Population Survey (CPS) March Supplements for the years from 1983 to 1999. Table 1 shows the occupational groups and the distribution of these groups in the sample. CPS data are available as far back as 1969 but the regional descriptors are far less detailed in the early part of the sample and these observations were unusable. The occupational group definitions changed substantially in 1983 making it difficult to define a consistent set of occupational groups before 1983 .

We identify a sample of males employed in occupations that are either directly or closely related to professional sports. ${ }^{5}$ We used the detailed occupational codes in the CPS data to identify two broad occupational groups in the sample: workers employed in jobs directly related to professional sports and workers employed in jobs indirectly related to professional sports. The occupations in the top panel of Table 1 are assumed to be directly related to professional sports and the occupations in the bottom panel are assumed to be indirectly related to professional sports.

The individuals in occupations directly related to professional sports worked in occupations that would be employed in sports facilities or in closely related establishments: announcers, ushers, and athletes. The exact description of these occupational groups can

\footnotetext{
${ }^{5} \mathrm{As}$ is common in the labor literature, we focus exclusively on males to avoid econometric problems associated with volatility in female labor force participation.
} 
be found in the data appendix. Note that the athletes occupation includes coaches, scouts, referees and competitors, and that even among the athletes we cannot distinguish individuals employed in the sports facilities from, say, a jockey at the local race track or a personal trainer living in the city.

Table 1: Occupational Groups

\begin{tabular}{lrr}
\hline \hline Occupation previous year & Freq. & Percent \\
\hline Athletes and kindred workers & 318 & 0.88 \\
Announcers & 317 & 0.88 \\
Recreation workers & 138 & 0.38 \\
Attendants recreation and amusements & 535 & 1.49 \\
Ushers recreation and amusement & 254 & 0.71 \\
\hline Sales managers and proprietors retail trade & 17,229 & 47.91 \\
Sales clerks retail trade & 3,233 & 8.99 \\
Restaurant and bar managers & 796 & 2.21 \\
Bartenders & 1,101 & 3.06 \\
Waiters & 1,797 & 5.00 \\
Cooks & 6,559 & 18.24 \\
Food counter workers & 432 & 1.20 \\
Food service workers n.e.c. & 2,018 & 5.61 \\
Hotel Clerks & 182 & 0.51 \\
Maids and Housemen & 796 & 2.21 \\
Parking attendants & 253 & 0.70 \\
\hline Total & 35,958 & 100.00 \\
\hline
\end{tabular}

We also extracted individual level data for each person in the sample. The individual level variables include demographic characteristics like race, age, and education, various measures of earnings, and Metropolitan Statistical Area (MSA) descriptors. Using the MSA descriptors, and a variable created to identify the year the individual observation was collected, the CPS data were merged with a vector of sports environment variables indicating the presence of a professional franchise in football, baseball, or basketball in the MSA. Table 2 presents 
variable definitions and descriptive statistics for the full sample of 35,958 individuals. The observations are distributed uniformly over the 1983-1999 period.

Table 2: Summary Statistics

\begin{tabular}{lcc}
\hline \multicolumn{1}{c}{ Variable } & Mean & Std. Dev. \\
\hline Real Average Hourly Wage & 11.60 & 13.47 \\
Real Average Weekly Earnings & 543.82 & 523.44 \\
Age & 33.23 & 10.475 \\
Managerial Occupation & 0.501 & 0.500 \\
Attended College & 0.496 & 0.500 \\
Black & 0.075 & 0.263 \\
Other Minority & 0.066 & 0.249 \\
Part Time Worker & 0.088 & 0.283 \\
Seasonal Worker & 0.201 & 0.401 \\
NFL Franchise in MSA & 0.392 & 0.574 \\
NBA Franchise in MSA & 0.404 & 0.589 \\
MLB Franchise in MSA & 0.400 & 0.628 \\
Pro Sports Team in MSA & 0.433 & 0.496 \\
N & & 35958 \\
\hline
\end{tabular}

$86 \%$ of the individuals in the sample are white, $7.5 \%$ percent are black and $6.6 \%$ are members of other minority groups. Just under 50\% attended college. 9\% worked parttime and $20 \%$ worked less than the entire year, perhaps reflecting the seasonal nature of employment in the recreation industry.

Data on sports franchises and stadia came from information in Noll and Zimbalist (1997a), Quirk and Fort (1992) and the Information Please Sports Almanac (1996). Our sample includes 37 cities, the universe of MSAs that had either a professional football, basketball, or baseball franchise during the period. Roughly $40 \%$ of the individuals in the sample worked in a city that had a professional football, basketball, or baseball franchise, but there is considerable overlap, as only $43 \%$ of the individuals in the sample lived in a city that was home to one or more professional franchises. 


\section{Results and Discussion}

In this section we report the results of estimating Equation (1). We estimate the model pooling workers directly and indirectly related to the sports environment and for each of those groups separately. All of the empirical models also include city-specific dummy variables, time dummy variables for each year in the sample, and dummy variables identifying the occupation of the worker to control for unobservable local labor market conditions and aggregate economic factors that affect earnings in all cities in the sample. ${ }^{6}$ We report only the parameter estimates and standard errors for the individual-specific variables and the sports environment variables. The results for the full set of independent variables are available from the authors on request.

Table 3 shows the results of estimating Equation (1) for average weekly wages on the subsample of males employed in occupations directly related to professional sports. The dependent variable here differs from that of Carlino and Coulson (2004) whose regressand is the log of average hourly earnings. When we estimated the model explaining the log of average hourly earnings, estimated by dividing reported annual earnings by the product of average weekly hours worked and reported number of weeks worked last year, the results were similar to those shown on Table 3 . Those results are available on request.

The parameters on the individual-specific controls are precisely estimated and generally the expected sign. Age, our proxy for experience, increases average weekly wages suggesting positive returns to experience; age squared is negative and significant, indicating that the returns to experience eventually diminish. Blacks, other minorities, part-time workers and seasonal workers had lower average real weekly earnings than white, full-time workers. The educational variable is significant and of the predicted sign given that it measures the effect of education on wages relative to someone with at least a high school diploma. The model explained almost half of the observed variation in real average weekly earnings in the sample.

The parameters on the sports environment variables are of primary interest here. The parameter on the NFL indicator variable is positive and significant, suggesting that workers

\footnotetext{
${ }^{6}$ We also estimated the models including two-digit industry dummy variables instead of occupation-specific dummy variables. These results are not materially different than those reported here and are available upon request.
} 
Table 3: Cluster-Corrected Estimates of Equation (1)

Occupations Directly Related to Sports

Dependent Variable: $\log$ (Average Weekly Earnings)

\begin{tabular}{lcc}
\multicolumn{1}{c}{ Variable } & Coefficient & (Std. Err.) \\
\hline Age & $0.179^{* *}$ & $(0.024)$ \\
Age $^{2}$ & $-0.002^{* *}$ & $(0.000)$ \\
Attended College & $0.123^{* *}$ & $(0.045)$ \\
Black & $-0.094^{\dagger}$ & $(0.056)$ \\
Other Minority & $-0.240^{*}$ & $(0.094)$ \\
Part Time Worker & $-0.762^{* *}$ & $(0.060)$ \\
Seasonal Worker & $-0.504^{* *}$ & $(0.052)$ \\
NFL Franchise & $0.194^{* *}$ & $(0.053)$ \\
NBA Franchise & $0.293^{\dagger}$ & $(0.152)$ \\
MLB Franchise & $-0.565^{* *}$ & $(0.132)$ \\
Intercept & $2.556^{* *}$ & $(0.449)$ \\
$R^{2}$ & 0.49 & \\
$N$ & 1502 & \\
\hline Significance levels : & $\dagger: 10 \%$ & \\
& & $*: 5 \%$
\end{tabular}


living in MSAs with a professional football team and employed in occupations directly related to professional sports have higher real average weekly earnings than similar individuals in MSAs without an NFL franchise. The parameter on the MLB variable is negative and significant, suggesting that workers living in MSAs with a professional baseball team and employed in occupations directly related to professional sports have lower real average weekly earnings than similar individuals whose cities are without a baseball franchise. An NBA franchise also appears to raise weekly wages of men employed in occupations directly related to professional sports.

Coates and Humphreys (2003), (2001), (1999) focused on the overall impact of the sports environment rather than the effects of an individual franchise or sport. Supposing a city to host a team in each of the three professional leagues, one can sum the coefficients on the NFL, NBA, and MLB dummies to calculate the overall effect. ${ }^{7}$ The total is -0.078 , indicating that the effect of the three sports together is to reduce average weekly wages for those individuals working in occupations most closely linked to the professional sports environment by nearly $8 \%$ relative to otherwise identical workers in cities with no franchises. ${ }^{8}$

Table 4 shows the results for workers employed in occupations indirectly related to professional sports. Again, these workers - waitresses, bartenders, hotel and restaurant workers, and the like - are often those on whom proponents of stadium led growth focus their attentions. Proponents of sports stadiums as engines of economic growth claim that franchises attract customers to the eating and drinking establishments in the neighborhood of the stadium or arena and out of town visitors to the city's hotels. This added business is good for the workers in these establishments. The results for average weekly wages are consistent with this argument. Both an NFL and an MLB franchise have a positive and statistically significant impact on the average weekly wages of workers only indirectly linked to the sports environment. These effects are $6.2 \%$ and $3.2 \%$, respectively. Note that this means that workers in this group, employed in a city with an NFL franchise, earn $6.2 \%$ per week more than identical workers in cities without a franchise. The coefficient on the NBA variable in the

\footnotetext{
${ }^{7}$ The Coates and Humphreys (2003), (2001), (1999) analysis also includes the effects of entry and exit decisions of franchises, stadium construction, and stadium size in the sports environment.

${ }^{8}$ The overall effects on average hourly earnings are a reduction of about $20 \%$ which suggests that the presence of the franchises will tend to induce an increase in hours per week.
} 
Table 4: Cluster-Corrected Estimates of Equation (1)

Occupations Indirectly Related to Sports

Dependent Variable: $\log$ (Average Weekly Earnings)

\begin{tabular}{lcc}
\multicolumn{1}{c}{ Variable } & Coefficient & (Std. Err.) \\
\hline Age & $0.098^{* *}$ & $(0.003)$ \\
$\mathrm{Age}^{2}$ & $-0.001^{* *}$ & $(0.000)$ \\
Managerial Occupation & $0.608^{* *}$ & $(0.063)$ \\
Attended College & $0.133^{* *}$ & $(0.008)$ \\
Black & $-0.106^{* *}$ & $(0.015)$ \\
Other Minority & $-0.064^{\dagger}$ & $(0.033)$ \\
Part Time Worker & $-0.584^{* *}$ & $(0.019)$ \\
Seasonal Worker & $-0.343^{* *}$ & $(0.017)$ \\
NFL Franchise & $0.062^{* *}$ & $(0.018)$ \\
NBA Franchise & 0.005 & $(0.028)$ \\
MLB Franchise & $0.032^{*}$ & $(0.013)$ \\
Intercept & $3.752^{* *}$ & $(0.091)$ \\
$R^{2}$ & 0.52 & \\
$N$ & 31,483 & \\
\hline Significance levels : & $\dagger: 10 \%$ & $*: 5 \%$ \\
\end{tabular}


average weekly wages equation (Table 4 ) is positive but both statistically and practically insignificant.

Finally, consider what happens to wages when there is a change in franchise status in the MSA. Table 5 reports the results of estimating Equation (1) for all occupations when the sample is restricted to individuals living in a MSA that experienced a professional sports franchise change over the sample period. The league dummies in this model identify the effects of the presence of each professional sports franchise on wages in a given city after acquiring a franchise or before losing one. The NFL dummy variable is statistically significant and positive in this specification, indicating that wages of workers in industries directly or closely related to professional sports are about $6.3 \%$ higher when an NFL franchise is in town than when it is not. Neither of the NBA or MLB variables is statistically significant at conventional levels, but both estimates have positive signs. These results suggest that the $6.3 \%$ increase in average weekly earnings brought by the NFL franchise is split into an increase in hourly earnings of $4.5 \%$ and an increase in hours of $1.8 \%$.

We also estimated Equation (1) using a pooled sample of individuals in all of the occupations. In these pooled results, available upon request, the results on the human capital and experience variables are consistent with wage equations in the literature. Wages, whether hourly or weekly, rise with age but at a decreasing rate, are higher for college graduates than for non-college graduates, are lower for African-Americans and for other minorities, and for part-time and seasonal workers. There are significant differences across MSAs, between years, and by occupation. In these pooled regressions, the presence of an NFL franchise has a positive and significant effect on average weekly real wages. These results contrast with those of Carlino and Coulson (2004) whose estimates on a sample including all workers across all industries and occupations, both males and females, are never significant and frequently negative in sign. Coefficients on the presence of an NBA or MLB franchise are positive but not statistically significant at conventional levels.

The results clearly suggest that the NFL has effects that are generally not found for either NBA or MLB franchises. The NFL variable is individually significant in the wage regressions for individuals in occupations directly and indirectly related to professional sports and in the wage regression for all occupations in MSAs that gained or lost NFL franchises. The 
Table 5: Cluster-Corrected Estimates of Equation (1)

All Occupations, MSAs with Franchise Changes

Dependent Variable: $\log$ (Average Weekly Earnings)

\begin{tabular}{lcc}
\multicolumn{1}{c}{ Variable } & Coefficient & (Std. Err. $)$ \\
\hline Age & $0.101^{* *}$ & $(0.010)$ \\
Age $^{2}$ & $-0.001^{* *}$ & $(0.000)$ \\
Managerial Occupation & $0.359^{* *}$ & $(0.080)$ \\
Attended College & $0.157^{* *}$ & $(0.025)$ \\
Black & $-0.089^{* *}$ & $(0.029)$ \\
Other Minority & $-0.118^{*}$ & $(0.047)$ \\
Part Time Worker & $-0.513^{* *}$ & $(0.043)$ \\
Seasonal Worker & $-0.291^{* *}$ & $(0.024)$ \\
NFL Franchise & $0.063^{* *}$ & $(0.021)$ \\
NBA Franchise & 0.029 & $(0.025)$ \\
MLB Franchise & 0.033 & $(0.031)$ \\
Intercept & $3.581^{* *}$ & $(0.148)$ \\
$R^{2}$ & 0.53 & \\
$N$ & 6,300 & \\
\hline Significance levels : & $\dagger: 10 \%$ & $*: 5 \%$ \\
& $* *: 1 \%$
\end{tabular}


NBA variable is only significant, and at the ten percent level, in the wage regression for occupations directly related to professional sports. The MLB variable is significant and negative for occupations directly related to professional sports, and significant and negative for occupations indirectly related to professional sports. The presence of professional sports franchises appear to influence the wages of individuals working in activities linked to the sports environment. However, it is most likely that the sporting environment affects the wages of workers who are directly involved in sports and recreation activities.

These findings have some intuitive appeal. The NFL has a limited number of games virtually all of which are played on the weekend. This enables individuals to treat attendance at an NFL game as a more special type of outing than, say, an NBA game which is likely to be played on a weeknight when kids have school the next day and five times more frequent than the NFL games. MLB games are the most frequent of all, with 81 home dates, and there are long stretches of the season in April through June and September during which games are played on school nights.

Table 6: Summary: Joint Significance Tests

\begin{tabular}{|c|c|c|c|}
\hline & Direct & Indirect & Change \\
\hline$N F L+N B A+M L B=0$ & Accept & Reject * & Reject * \\
\hline$N F L+N B A=0$ & Reject ${ }^{* *}$ & Accept & Reject $^{\dagger}$ \\
\hline$N F L+M L B=0$ & Reject $^{* *}$ & Reject * & Reject * \\
\hline$N B A+M L B=0$ & Reject $^{\dagger}$ & Accept & Reject $^{\dagger}$ \\
\hline
\end{tabular}

Coates and Humphreys (2003), (2001), (1999) aggregated the effects of franchises in the NBA, NFL, and MLB, along with stadium and arena construction and capacities in computing the overall effects of the sports environment. Table 6 summarizes the results of tests of the null hypothesis that the sum of the coefficients on the NFL, NBA, and MLB variables equals zero. For the workers employed in jobs directly related to the sports environment, having a franchise in all three sports results in no net gain or loss from professional sports. However, having a franchise from any two of the three leagues does have a significant impact on wages. When an MLB franchise is one of the two, the effect is almost surely negative 
overall.

For those workers only indirectly connected to the sports environment, the clear message of the joint hypothesis tests is that the individual significance of the NFL variable is often strong enough to carry with it a weak effect from MLB, and the two together can overcome the insignificance of the NBA variable. Individually, however, neither NFL nor MLB has a sufficiently powerful effect to carry NBA with it. In the case of the indirectly connected workers, the total effect is always positive when it is significant.

In the change specification, the NFL effect is sufficiently strong to carry with it the weak effects of the NBA and MLB. Again, the total effects of franchises in multiple sports is positive, indicating that workers from cities that gain franchises, especially NFL franchises, will see their hourly and weekly wages rise. This effect is particularly prominent for workers in activities indirectly related to sports.

That the effects of franchises on wages in different sectors of the economy are different should not be surprising. Some activities will be closer substitutes for professional sports than others, and some activities will be closer complements with professional sports. Siegfried and Zimbalist (2000) describe possible channels through which professional sports might decrease earnings of workers in some occupational groups. Especially relevant for this study is the "Substitution Effect" resulting from the budget constraint faced by consumers. Sports competes with other entertainment goods and services in the local economy. Our analysis suggests that spending on MLB substitutes for spending on other types of recreation, as workers in the occupations like "Attendants in recreation and amusements," "Recreation workers," and "Ushers in recreation and amusements" see their wages reduced when a MLB franchise is town over what they would be in towns without the baseball team.

Some activities are generally considered complements with a professional sporting event. While each dollar spent at the ballpark is a dollar not spent on a meal in a local restaurant, it is possible that people take the ball game as an opportunity to eat out that they would not otherwise experience. Our prior belief is that sports would reduce consumer spending at local bars and restaurants across a metropolitan area and could lower earnings of employees at these establishments. Evidence in this paper is that an NFL franchise, and possibly an MLB franchise, lead to higher wages in these indirectly related occupations. The evidence 
is, therefore, that professional sports is a complement rather than a substitute for dinners out, hotel stays, and retail sales. The evidence also suggests that a substantial portion of the effect comes from additional hours of work rather than higher hourly wages.

These results do not necessarily argue for public subsidies for professional sports facilities and franchises. The analysis here has focused only on males in occupations that are closely related to the professional sports environment. Using a similar methodology, Carlino and Coulson (2004) found no effect of the NFL on wages across all occupations and industries. Using more aggregate data, Coates and Humphreys (2003),(2001), (1999) generally find no effect or even broad harmful effects of the sports environment on incomes. However, the results here do lend support to the wide-spread belief that some narrowly focused sectors of the local economy may have higher income because there is an NFL franchise in town than they would if there were no such franchise.

This paper does not address the non-market value to the city of having the professional sport franchises. Economists have long recognized the important non-pecuniary consumption benefits associated with professional sports. Residents of cities clearly derive significant utility from access to professional sports, and these consumption benefits may justify hundreds of millions of dollars of public spending on new sports facilities. However, the results presented here reinforce the point that public subsidies for professional sports facilities and franchises are not justified by the claims of direct or indirect economic benefits in the form of higher wages frequently put forth by the proponents of these subsidies.

The results in this paper represent a robustness check on previously reported results. Much of the retrospective evidence on the economic impact of sports on local economies, including the findings of a negative impact, are based on aggregated data. Mostly, this data is published by the Bureau of Economic Analysis as part of the Regional Economic Information System (REIS). These data are aggregated across individuals in specific geographical areas. Aggregation of this type can lead to a number of econometric problems, as was pointed out by Zellner (1966). Serial correlation is another common econometric problem associated with aggregate data. The similarity of the results in this paper and those obtained from aggregate data suggest that previously published results do not have serial correlation problems.

Further, results from aggregate data depend on the sampling methodology underlying 
the REIS. Obtaining quantitatively similar results from a different data set composed of observations at a different level of aggregation, and using a different empirical modeling approach, suggests that previously published results are robust to problems stemming from the data and the model specification.

In this paper we have examined the impact of professional sports on average weekly earnings of a sample of workers in narrow occupational groups drawn from the Current Population Survey March Supplement. These occupational groups are among those that proponents of public funding of professional sports claim will benefit economically from subsidies. The approach here contrasts with that in previous research which focused on aggregate measures of income. However, the results of this study confirm conclusions of earlier research that the overall sports environment is frequently statistically significant as a determinant of earnings. However, the results also show that the effects of the sports environment differ across job-types. For example, for workers employed in retail occupations, annual earnings rise on average due to the presence of professional sports, but workers in other areas of recreation and amusements may find their wages lower by the presence of professional sports. 


\section{References}

Baade, R. A. (1996). Professional sports as catalysts for metropolitan economic development. Journal of Urban Affairs 18(1), 1-17.

Baade, R. A. and R. F. Dye (1988). Sports stadiums and area development: A critical review. Economic Development Quarterly 2(3), 265-275.

Baade, R. A. and R. F. Dye (1990). Stadiums and professional sports on metropolitan area development. Growth and Change 12(114), 1-14.

Baade, R. A. and A. R. Sanderson (1997). The employment effect of teams and sports facilities. In R. G. Noll and A. Zimbalist (Eds.), Sports, Jobs and Taxes: The Economic Impact of Sports Teams and Stadiums, pp. 92-118. Washington, D. C.: Brookings Institution.

Carlino, G. and N. E. Coulson (2004). Compensating differentials and the social benefits of the nfl. Journal of Urban Economics 56(1), 25-50.

Coates, D. and B. R. Humphreys (1999). The growth effects of sports franchises, stadia and arenas. Journal of Policy Analysis and Management 18(4), 601-624.

Coates, D. and B. R. Humphreys (2001). The economic consequences of professional sports strikes and lockouts. Southern Economic Journal 67(3), 737-747.

Coates, D. and B. R. Humphreys (2003). The effect of professional sports on earnings and employment in the services and retail sectors in u.s. cities. Regional Science and Urban Economics 33(2), 175-198.

Diamond, C. and M. Gerety (1995, May). Flexible form methods for measuring rent gradients. Journal of Regional Science 35(2), 245-266.

Houghton Mifflin Co. (1996). The Information Please Sports Almanac. Boston, MA: Houghton Mifflin Co.

Moulton, B. (1990). An illustration of the pitfall in estimating the effects of aggregate variables on micro units. The Review of Economics and Statistics 72(2), 334-338. 
Murphy, K. M. and F. Welch (1992). The structure of wages. Quarterly Journal of Economics 107(1), 285-326.

Noll, R. G. and A. Zimbalist (1997a). Build the stadium, create the jobs! In R. G. Noll and A. Zimbalist (Eds.), Sports, Jobs and Taxes: The Economic Impact of Sports Teams and Stadiums, pp. 1-54. Washington, D. C.: The Brookings Institution Press.

Noll, R. G. and A. Zimbalist (Eds.) (1997b). Sports, Jobs and Taxes: The Economic Impact of Sports Teams and Stadiums. Washington, DC: The Brookings Institution Press.

Quirk, J. P. and R. D. Fort (1992). Pay Dirt: The Business of Professional Team Sports. Princeton, NJ: Princeton University Press.

Ridker, R. G. and J. A. Henning (1967). The determinants of residential property values with special reference to air pollution. The Review of Economics and Statistics 49(1), $246-257$.

Roback, J. (1982). Wages, rents, and the quality of life. Journal of Political Economy $90(6), 1257-1278$.

Rosentraub, M. S. (1997). Major League Losers: The Real Cost of Sports and Who's Paying For It. New York, NY: Basic Books.

Rosentraub, M. S., D. Swindell, M. Przybylski, and D. R. Mullins (1994). Sport and downtown development strategy: If you build it, will jobs come? Journal of Urban Affairs 16(3), 221-239.

Siegfried, J. and A. Zimbalist (2000). The economics of sports facilities and their communities. Journal of Economic Perspectives 14(3), 95-114.

Topel, R. H. (1986). Local labor markets. Journal of Political Economy 94(3), 111-143.

Wooldridge, J. R. (2003). Cluster-sample methods in applied econometrics. American Economic Review 93(2), 133-138.

Zellner, A. (1966). On the aggregation problem: A new approach to a troublesome problem. In K. A. Fox (Ed.), Economic Models, Estimation, and Risk Programming: Essays in Honor of Gerhard Tintner, pp. 335-62. New York, NY: Springer-Verlag. 


\section{Appendix: Occupational Group Descriptions}

The following are the Census Occupation Codes (SOC), titles and descriptions for the occupational groups that comprise the sports and recreation group in the sample.

\section{Announcers}

27-3011/280 Radio and Television Announcers

"Talk on radio or television. May interview guests, act as master of ceremonies, read news flashes, identify station by giving call letters, or announce song title and artist."

27-3012/280 Public Address System and Other Announcers

"Make announcements over loud speaker at sporting or other public events. May act as master of ceremonies or disc jockey at weddings, parties, clubs, or other gathering places."

\section{Athletes}

27-2021/272 Athletes and Sports Competitors

"Compete in athletic events."

27-2022/272 Coaches and Scouts

"Instruct or coach groups or individuals in the fundamentals of sports. Demonstrate techniques and methods of participation. May evaluate athletes' strengths and weaknesses as possible recruits or to improve the athletes' technique to prepare them for competition."

27-2023/272 Umpires, Referees, and Other Sports Officials

"Officiate at competitive athletic or sporting events. Detect infractions of rules and decide penalties according to established regulations. Include all sporting officials, referees, and competition judges."

\section{Ushers}


39-3031/442 Ushers, Lobby Attendants, and Ticket Takers

"Assist patrons at entertainment events by performing duties, such as collecting admission tickets and passes from patrons, assisting in finding seats, searching for lost articles, and locating such facilities as rest rooms and telephones."

39-9032/174 Recreation Workers

"Conduct recreation activities with groups in public, private, or volunteer agencies or recreation facilities. Organize and promote activities, such as arts and crafts, sports, games, music, dramatics, social recreation, camping, and hobbies, taking into account the needs and interests of individual members." 